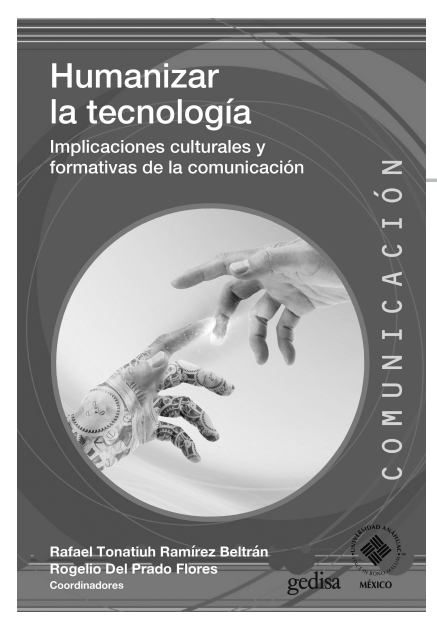

Elba Aurora Castro Rosales

Universidad de Guadalajara

Av. Juárez núm. 976, Col. Centro, C.P. 44100,

Guadalajara, Jalisco, México

Editor: Rogelio del Prado Flores

\section{Humanizar la tecnología. Implicaciones culturales y formativas de la comunicación}

Ramírez Beltrán, R. T.y

Del Prado Flores, R. (Coords.). (2019).

Humanizar la tecnología. Implicaciones

culturales y formativas de la comunicación.

Barcelona, España: Gedisa-Universidad

Anáhuac México.

elba.maestria@gmail.com

https://doi.org/10.36105/stx.2019n3.10

E

1 libro arranca con una mirada franca y reflexiva sobre el presente desafiante.

Es posible advertir que la llamada sociedad de la información no es sinónimo ni de paz, ni de progreso - siempre existe el riesgo de que las palabras y los mensajes se conviertan en ruido o en agresión-, como tampoco disponer de mucha información hace a un hombre más sabio. Prevalece el miedo, la inseguridad, y la desconfianza entre los individuos (p. 20).

Con una batería de 15 preguntas, los coordinadores abren el apetito para saborear el platillo intelectual que tenemos en frente, aquí algunas preguntas (p. 26).

¿Qué significa la comunicación, la cultura y la formación ante la avalancha de transformaciones que ha traído el imparable mundo digital? ¿Esta nueva forma de comunicación está empeorando o mejorando la calidad de nuestras vidas? 
En 230 páginas, los coordinadores reúnen a 11 autores, que participan, a veces en más de algunas de las cuatro partes que forman el libro, como son:

1. Comunicación y educación

2. Comunicación y participación ciudadana

3. Campo crítico de la comunicación y profesiones

4. Recepción crítica y lenguaje

Estas partes están conformadas por capítulos que basados en la reflexión de la experiencia han desarrollado un abordaje virtual o que experimenta la virtualidad en distintos contextos y finalidades de un proceso de comunicación. El libro provoca un diálogo entre quienes participan en los procesos formativos, quienes reflexionan sobre la sociedad a partir de la función mediacional de la comunicación y quienes tienen en sus manos la formación de comunicadores. Se trata de hacer un tejido analítico en el que cavilan asuntos como las transformaciones de las profesiones y de la misma vida cotidiana por el uso, apropiaciones e interacciones digitales; pero también la discusión se extiende a los terrenos del uso de las plataformas de los procesos de la educación a distancia, cursos en línea, asesorías remotas con voz y video en tiempo real, entre otras experiencias. Asunto que he de anotar, es de alta pertinencia al atender un fenómeno doble: la comunicación educativa, con mediaciones a distancia.

En primer lugar destaco la cantidad de datos actualizados sobre el uso de las redes. El $80 \%$ de las personas en México se comunican por internet, fundamentalmente por medio de códigos visuales y de voz. $79 \%$ de los usuarios de internet son jóvenes. El uso primordial es de entretenimiento y compras en línea.

Sólo esos datos documentan mi resistencia a usar redes sociales en lo personal y a mi carácter marginal en el uso de estos implementos, pero me hace apreciar aún más la postura del mismo Dr. Rafael Tonatiuh, quien se ha resistido al uso del teléfono celular, sin que ello le impida ser un personaje crítico y activo en el Facebook.

El uso de los aparatos electrónicos y plataformas no deberían decrecer la calidad educativa, pero en México, nos dicen Tonatiuh y Anaí Sánchez, tiene implicaciones catastróficas. Las notificaciones son un elemento de alerta al que parece no estamos predispuestos biológicamente a ignorar, por lo que son un elemento que no se debe desdeñar, pues rompen con la dinámica del aula al distraer de manera importante la atención de los estudiantes, especialmente del nivel básico. ¿Cómo convertir esta desventaja en un proceso de educomunicación, concepto que nace en América Latina y se extiende a Europa? Eso es uno de los 
aportes que hacen los autores. En seguida, Rogelio del Prado Flores y Luz Moreno harán una contribución para responder y detonar otras reflexiones: la formación de capacidades como la lectoescritura y la ética. Se robustecen las discusiones sobre la cultura escrita, la lectura compartida como espacio societal que ayuda a crecer la esperanza de una cultura consciente de su presente histórico y de su futuro.

Estamos ya en el terreno de la participación ciudadana. Así comienza la segunda parte del libro. Roberto López y María Cristina Rodríguez discuten sobre lo que significa participar para ser ciudadanos en un lugar que puede ser desterritorializado, pero participativo, lo que configura también nuevas concepciones de comunidad y de proyectos para emprender ciudadanía en el espacio de la significación de las luchas. Al respecto, en el capítulo 4 Roberto López y José Luis Flores, ahondan en lo expuesto a partir del ejemplo de las redes sociales de los venezolanos en México, quienes han construido espacios de colaboración en línea y de ciberprotesta. En su capítulo no dejan de reflexionar concienzudamente sobre el concepto de comunicación para enmarcar la discusión del fenómeno sociocultural que significa. Puesta la cancha, los autores discuten al respecto caracterizando el advenimiento de los cibermovimientos sociales.

Aquí es donde observamos un salto de profundidad teórica del libro. Arribamos a la tercera parte, al campo crítico de la comunicación y las profesiones. Rafael Tonatiuh y Cristina Barroso abren el tema reflexionando sobre la interculturalidad mediante un estudio de caso a partir de la comunicación digital en un corporativo transnacional. El tema abre nuevos horizontes a un rostro del estudio de la comunicación que es poco visible en la arena académica: la dimensión organizativa (que define roles, funciones y producción simbólica referente a ello y al alcance de los metaobjetivos de la empresa). Los autores nos dicen que en este ejercicio comunicacional hay temas que se remueven a partir de la era digital y los modos de participación que interpelan a las estructuras organizacionales y de liderazgo.

En el siguiente capítulo, Rogelio del Prado y Mariana Chávez, aluden a otro ángulo de la reflexión y producción comunicacional: la ética periodística en una época de convergencia. ¿Convergencia? Sí, de las funciones societales de este concepto en la configuración del presente de las sociedades. Los autores tejen una red teórica para comprender cada uno de los rostros que los periodistas tejen en la sociedad produciendo mensajes, en sus modos y medios, tanto como en sus contenidos y formas de construcción de los mensajes.

Estas discusiones ponen de relieve algunas construcciones en torno a la ética y el papel social del periodismo, como la posverdad, las fake newes, el infoentretenimiento y la alfabetización digital, entre otras.

Finalmente, en la parte 4 del libro, dedicado a deliberar sobre la reflexión crítica y el lenguaje, Rafael Tonatiuh, junto con Elías Aguilar exploran, en el capítulo 7 una nueva teoría, 
sobre la lectura de las noticias y la configuración de la democracia: el framing. El concepto nos deja claro que la política tiene un rostro mercadológico pero que los filtros de recepción aún no son del todo manipulables. Explicar la insatisfacción de la democracia es la clave de este capítulo que devela la función política de la comunicación. Por último, en el capítulo 8, Rogelio del Prado y Silvia Zapata cierran con un capítulo que zanja reflexiones en torno a la recepción activa y, por tanto, la educación crítica de medios. Los autores dialogan con Alfred Schutz y Anthony Gidens, con este insumo y otros diálogos con teóricos de la comunicación, ellos construyen o confluyen en determinar seis dimensiones en las que centran al sujeto alfabetizado mediáticamente; finalizarán con sentar las bases para la generación de nuevos modelos narrativos, ficción televisiva y transmediación.

Los contenidos nos dejan un mapa interesante de retos, tanto como de invitaciones a cavilar nuestras propias prácticas y el presente que vivimos. Me deja pensando, por ejemplo, en enriquecer la noticia que tuve en este recinto hace unos días, que el periódico El País, de excelentes contenidos, anunció que ya no emitiría sus ejemplares impresos... Me hace eco pensar que puedo ser ciudadana, aunque marginal, continuando la lucha por exigir contenidos interesantes, aunque para ello las formas ya no tengan que ver con leer y escribir del siglo XX.

Muchas gracias Dr. Ramírez, Dr. Del Prado y colegas, por esta producción que interna al debate de la comunicación desde una profunda convicción política y educativa. 